\title{
IDENTAL
}

\section{Success in crown and bridge work}

\author{
G. Gilmour ${ }^{1}$
}

\author{
All practitioners wish for success in their restorative work mainly due to their \\ desire to do the best for their patients, but increasingly the achievement of \\ success, ie the avoidance of failure, is felt to be necessary to avoid the spectre \\ of litigation. The number of patient-led litigation cases is on the increase and \\ the majority involve crown and bridge work.
}

It is surprising in legal cases how many patients state that they were told 'the restoration will last a lifetime' by the dentist and feel aggrieved by its failure, hence the complaint. It is difficult to imagine any dental practitioner confidently predicting that any restoration would last a lifetime and such a statement would certainly not be evidence based! Could it be that dentists do not actually say the words 'last a lifetime' but somehow transmit this idea in a non verbal way to the patient either through enthusiasm and pride in their work or by saying nothing about prognosis and thereby leading the patient to an unrealistic expectation?

It is good practice to advise patients as early as possible that all restorations require to be maintained and eventually replaced. If possible, retrievability should be built into the design, eg a resin bonded bridge may be provided initially with a view to the provision in the future of a conventional full coverage bridge when the clinical circumstances dictate.

Failure in restorative dentistry can often be traced to the treatment planning stage and of course much can be written about treatment planning and its various phases. It can be useful however to summarise the key elements of treatment planning as:

1. Determining patient's expectations 2. Ensuring the health of the soft tissues before treating the hard tissues.

${ }^{1}$ Consultant in Restorative Dentistry, Mayday University Hospital, London Road, Croydon, CR7 7YE Correspondence to Mr G. Gilmour

Email:graham.gilmour@mayday.nhs.uk

doi:10.1038/sj.bdj.4811043

๑ British Dental Journal 2004; 196: 306
This article highlights the paper being presented at 14.00 on Saturday, 8 May 2004 in the Windsor Hall at The British Dental Conference \& Exhibition 2004 being held at the Bournemouth International Centre

Many examples of failure in crown and bridge work can be cited where the cause has been poor periodontal support or an unhealthy pulp.

There is an oft-repeated quote by De Van in 1956 who wrote -

'We should seek to preserve what remains rather than replace what is lost.'

This concept is similar to the principle that in treatment we should do no harm. The literature in restorative dentistry, however, is rich in examples of publications describing the incidence of the need for endodontic treatment after crown or bridge provision on vital teeth, with percentages of post treatment non vitality ranging from 3 to $21 \%$.

There must therefore be a positive indication for replacing a missing tooth or teeth by a fixed restoration in order to make the potential risk, expense etc. worthwhile.

It is generally accepted that the indications for replacing missing teeth are as follows:

- Function

- Comfort

- Occlusal stability

- Aesthetics.

In many cases it is the desire for aesthetic improvement which is the driver for the patient to seek treatment and it is therefore incumbent on the dental practitioner to provide an appropriate cosmetic appearance. Unfortunately patients' dissatisfaction with the final appearance is a common cause of complaint and there can be a number of reasons for this. The first and obvious reason is that the shade or shape of prosthetic tooth or position of the restoration is out of harmony with the rest of the dentition and clearly this should be corrected by the practitioner.

More difficult to manage are the situations either where the patient's expectations of excellence in appearance are far beyond anything which could reasonably be provided, or the patient's view of aesthetics is 'individual'.

It is important to recognise these potential problems at the treatment planning stage and act accordingly - even to the extent of declining to treat the patient if it is felt that they are unlikely ever to be satisfied - and consider an onward referral.

In restorative dentistry 'beauty is in the eye of the owner'!

The British Dental Conference \& Exhibition 2004 is being held at the Bournemouth International Centre between Thursday 6th and Saturday 8th May 2004

Contact: DMS (Delegate Management Services) for further information:

Tel: 08701666625 or +44 (0) 1252771425

Fax: 08705228890 or +44 (0) 1252771790

For the latest update on the agenda and to download the programme visit: www.bda-events.org 